\title{
Balance deficits and ADHD symptoms in medication-naïve school-aged boys
}

This article was published in the following Dove Press journal:

Neuropsychiatric Disease and Treatment

15 January 2014

Number of times this article has been viewed

\author{
Jana Konicarova' \\ Petr Bob ${ }^{1,2}$ \\ Jiri Raboch' \\ 'Center for Neuropsychiatric \\ Research of Traumatic Stress, \\ Department of Psychiatry and UHSL, \\ Ist Faculty of Medicine, Charles \\ University, Prague, Czech Republic; \\ ${ }^{2}$ Central European Institute of \\ Technology, Faculty of Medicine, \\ Masaryk University, Brno, Czech \\ Republic
}

Background and objectives: Functional disturbances developed early in life include balance deficits which are linked to dysfunctions of higher levels of cognitive and motor integration. According to our knowledge, there are only a few studies suggesting that balance deficits are related to behavioral disturbances in attention-deficit/hyperactivity disorder (ADHD).

Methods: We tested the extent to which balance deficits were related to ADHD symptoms in 35 medication-naïve boys of school age (8-11 years) and compared the results with a control group of 30 boys of the same age.

Results: ADHD symptoms in medication-naïve boys had specific relationships to disturbances of postural and gait balance.

Conclusion: To our knowledge, this study provides the first evidence in the medical literature for a direct relationship between ADHD symptoms and balance deficits, that cannot be attributed to medication and the presence of any neurological disease.

Keywords: ADHD, balance deficits, conduct problems, developmental disorders, inhibitory deficits, impulsivity

\section{Introduction}

Functional disturbances from various stages of development that influence cognitive and motor functions occur in several neuropsychiatric disorders ${ }^{1,2}$ and also in attention-deficit/hyperactivity disorder (ADHD). ${ }^{3,4}$ These findings suggest that children with ADHD demonstrate impaired motor performance and postural and gait balance abnormalities, that are implicated as important factors of hypofrontality, ${ }^{3-5}$ and may be related to cerebellar inhibitory deficits. ${ }^{1,5-7}$ Hypofrontality is frequently interpreted as indicative of delayed maturation of frontal lobe function related to a compensatory response of the basal ganglia, cerebellum, and some other brain structures in patients with ADHD. ${ }^{8,9}$ These findings also suggest that attentional and executive functions related to reduced activation in the right inferior frontal cortex, anterior cingulate cortex, supplementary motor area, and other regions are linked to inhibitory deficits. ${ }^{10}$

According to current findings there is no evidence to which extent balance deficits in the form of soft neurological signs are related ADHD symptoms. With respect to this we tested a hypothesis to which extent balance deficits will be related to ADHD symptoms in 35 boys medication-naïve in the school age in comparison to the control group 30 of boys without ADHD of the same age.
Department of Psychiatry, Charles

University, Ist Faculty of Medicine,

Ke Karlovu II, 12800 Prague,

Czech Republic

Email petrbob@netscape.net 


\section{Methods}

\section{Participants}

Within the framework of ELSPAC (European Longitudinal Study of Parenthood and Childhood) study data of 35 boys (mean age 9.28, $\mathrm{SD}=1.10$ age range 8-11) with $\mathrm{ADHD}$ diagnosed according to Diagnostic and Statistical Manual of Mental Disorders-IV criteria characterizing their balance deficits and psychometric measures of ADHD symptoms were collected. All the patients were medication-naïve and their assessment was done before starting treatment. The ADHD diagnosis was combined hyperactive-inattentive subtype with occurrence of ADHD-based learning difficulties. Exclusion criteria were other child psychiatric and neurological disorders, including conduct disorder, involuntary movement disorders, tic disorders, anxiety disorders with potential for tremors that might affect posture and gait balance, substance abuse, and previous exposure to stimulant medication. Recruitment of the untreated patients was based on consecutive visits in the clinic, whereas the control group was recruited using school advertisements. The control group of 30 boys without ADHD (mean age $9.46 \pm 1.07$ years, range 8-11 years) fulfilled the same exclusion criteria. Parents of all the participants gave written informed consent and the research was approved by the Ethical Committee of Charles University, 1st Faculty of Medicine within the framework of collaboration of the project ELSPAC, the project Center for Neuropsychiatric Research of Traumatic Stress, and the project MSM0021620849 at Charles University.

\section{Measurement of balance deficits}

To assess balance deficits, we used four selected items from the Physical and Neurological Examination for Soft Signs Scale (PANESS) by Denckla, ${ }^{11}$ which can be used in children and adolescents. PANESS is an observational scale with 21 tasks which includes items also useful for measurement of balancing deficits:

Standing, eyes closed - Item 9 Sustentation Postures/ Stations: "Now I want you to put one foot in front of the other, just as you did for walking the straight line forward and backwards right now, and close your eyes. Stay that way as long as you can, or until I tell you to relax". Time with stopwatch duration of success up to $20 \mathrm{sec}$. Score: Use stopwatch-determine time to score in groupings (see form) of duration. Code for tendency to fall (1) and for bringing arms up and out to balance (1). Scoring is on the scale $0,1,2,3$.

Walking forward - Item 7 Tandem Walking: "Now put your heel against your toe and walk to the end, staying on the line." Score: Not placing the heel to toe or missing the line completely constitutes an error. Code number of gaps, misses, failure to place heel to toe. Scoring is on the scale $0,1,2,3$.

Walking backward - Item 8 Tandem Walking: "Now do the same thing backwards." Score as in test for forward tandem gait, on the scale $0,1,2,3$.

Walking forward, eyes closed - Item 7 Tandem Walking: the same procedure and scoring, but with eyes closed. Scoring is on the scale $0,1,2,3$.

Balancing deficits were measured twice by two independent examiners and were averaged.

\section{Psychometric measure of ADHD symptoms}

A frequently used measure of ADHD symptoms is Conners' Parent Questionnaire (CPQ). ${ }^{12,13}$ The CPQ is 93-item scale of symptoms that are most commonly associated with behavioral disorders and related to children and adolescents (aged 3-17 years). The CPQ can measure treatment changes and assess outcomes.

A total score and subscale scores based on the factor structure of the questionnaire can be calculated: I. Conduct problems (items 39, 40, 41, 47, 48, 51, 69); II. Anxiety (items 8, 9, 10, 11, 42, 43, 64); III. Impulsivity-hyperactivity (items 78, 80, 81, 82, 83, 84, 89, 90); IV. Learning problems (items 45 , 62, 63, 67); V. Psychosomatic difficulties (items 6, 21, 22 , 23, 24); VI. Perfectionism (items 3, 76, 77, 78); VII. Antisocial behavior (items 71, 72, 73, 75); and VIII. Muscular tension (items 12, 13, 14, 36). The symptoms were rated on a 4-point Likert scale (from 0-3) by either one or both parents of the child. The measurements of ADHD symptoms rated by parents were independently confirmed by a physician or psychologist who treated the child.

\section{Statistical analysis}

Statistical evaluation of scores of the measures of balance deficits and ADHD symptoms included Spearman correlation coefficients and the Fisher's exact test. To prevent Type 2 error, which would cause a failure to reject a false null hypothesis that ADHD symptoms are not linked to balance deficits, we performed power analysis and assessed the effect sizes characterizing the correlation coefficients. All the methods of statistical evaluation were performed using the Statistica software package, version 6 (StatSoft Inc, Tulsa, OK, USA).

\section{Results}

Results of the analysis showed that the scores for balance deficits with eyes closed were specifically related to ADHD symptoms measured by CPQ total score: standing, 
Table I Spearman correlations of balance scores and ADHD symptoms (CPQ and its subscales) in 35 boys with ADHD

\begin{tabular}{lllll}
\hline & $\begin{array}{l}\text { Standing, } \\
\text { eyes closed }\end{array}$ & $\begin{array}{l}\text { Walking } \\
\text { forward }\end{array}$ & $\begin{array}{l}\text { Walking } \\
\text { backward }\end{array}$ & $\begin{array}{l}\text { Walking forward, } \\
\text { eyes closed }\end{array}$ \\
\hline CPQ & $\mathbf{0 . 4 9}$ & 0.31 & 0.05 & $\mathbf{0 . 5 7}$ \\
I. Conduct problems & $\mathbf{0 . 5 3}$ & 0.19 & 0.01 & $\mathbf{0 . 4 0}$ \\
II. Anxiety & -0.01 & 0.25 & 0.09 & 0.15 \\
III. Impulsivity-hyperactivity & $\mathbf{0 . 4 7}$ & 0.24 & 0.02 & 0.26 \\
IV. Learning problems & 0.027 & 0.21 & 0.02 & 0.21 \\
V. Psychosomatic difficulties & 0.20 & 0.16 & 0.17 & $\mathbf{0 . 3 4}$ \\
VI. Perfectionism & -0.11 & 0.17 & 0.17 & -0.05 \\
VII. Antisocial behavior & 0.28 & 0.17 & 0.23 & 0.19 \\
VIII. Muscular tension & 0.32 & 0.16 & 0.13 & $\mathbf{0 . 5 3}$ \\
\hline
\end{tabular}

Notes: Bold Spearman correlation coefficients higher than 0.43 were significant at $P<0.0$ I, with the Fisher's exact test score $>0.46$. Spearman correlation coefficients higher than 0.33 were significant at $P<0.05$, with a Fisher's exact test score $>0.35$.

Abbreviations: ADHD, attention-deficit/hyperactivity disorder; CPQ, Conners' Parent Questionnaire.

eyes closed and CPQ, Spearman $\rho=0.49$; and walking forward, eyes closed and CPQ, Spearman $\rho=0.57$. Other results including power analysis are shown in Table 1. These correlations indicate that a significant proportion of ADHD symptoms are associated with balance deficits. The control group of 30 children manifested very rare and minor balance deficits that on the scale from 0 to 3 had maximum value 1 , which occurred in 3 cases in standing with eyes closed, in 1 case during walking back and in 5 cases during walking back with eyes closed. The same statistical analysis in the control group did not show significant relationships between reported minor balance deficits and minor ADHD manifestations that in healthy children occur very rarely.

\section{Discussion}

Several recent findings show that high proportions of children with ADHD exhibit motor abnormalities and altered balance. ${ }^{3,4}$ According to brain imaging studies, these deficits are related to disturbed prefrontal executive functions ${ }^{14-16}$ and abnormalities in cerebellar regions associated with balance and gait control caused by inhibitory deficits. ${ }^{3,5-7,17}$ In this context, results of this study are in agreement with data reported by Buderath et al, ${ }^{3}$ who found that balance abnormalities were most prominent during task performance in conditions with closed eyes, when due to reduced visual information subjects were primarily dependent on vestibular information. In similar conditions of reduced visual or proprioceptive information, balance-control abnormalities have also been found in children with cerebellar lesions, which suggests that the abnormal postural control is likely determined by difficulties integrating the multimodal sensory information needed for balance control. ${ }^{18}$ This influence of reduced sensory information on balance control is in agreement with other findings showing that visual information plays an important role in balance regulation ${ }^{19-22}$ and that similar effects of balance dysregulation may also cause conflicting visual information in patients with cerebellar deficits. ${ }^{23}$ These data are in agreement with findings that ADHD may be associated with a cerebellar dysfunction leading to balance problems. ${ }^{3,5,17}$

Results of this study support the hypothesis that balance deficits are linked to ADHD symptoms reflecting brain abnormalities related to higher levels of cognitive, motor, and vestibular integration. To our knowledge, these results also present the first evidence in the medical literature indicating a direct relationship between ADHD symptoms and balance deficits that cannot be attributed to medication and presence of any neurological disease.

\section{Acknowledgments}

The study was supported by project MSM0021620849 provided by the Czech Ministry of Education, the PRVOUK program provided by Charles University, and the "CEITEC - Central European Institute of Technology" (CZ.1.05/1.1.00/02.0068) project from the European Regional Development Fund.

\section{Disclosure}

The authors report no conflicts of interest in this work.

\section{References}

1. Teicher MH, Tomoda A, Andersen SL. Neurobiological consequences of early stress and childhood maltreatment: are results from human and animal studies comparable? Ann N Y Acad Sci. 2006;1071:313-323.

2. Kolb B, Gibb R. Brain plasticity and behaviour in the developing brain. J Can Acad Child Adolesc Psychiatry. 2011;20(4):265-276.

3. Buderath P, Gärtner K, Frings M, et al. Postural and gait performance in children with attention deficit/hyperactivity disorder. Gait Posture. 2009;29(2):249-254. 
4. Ghanizadeh A. Predictors of postural stability in children with ADHD. J Atten Disord. 2011;15(7):604-610.

5. O'Halloran CJ, Kinsella GJ, Storey E. The cerebellum and neuropsychological functioning: a critical review. J Clin Exp Neuropsychol. 2012;34(1):35-56.

6. Teicher MH, Andersen SL, Polcari A, Anderson CM, Navalta CP, Kim DM. The neurobiological consequences of early stress and childhood maltreatment. Neurosci Biobehav Rev. 2003;27(1-2):33-44.

7. Heath RG, Franklin DE, Shraberg D. Gross pathology of the cerebellum in patients diagnosed and treated as functional psychiatric disorders. J Nerv Ment Dis. 1979;167(10):585-592.

8. Rubia K, Overmeyer S, Taylor E, et al. Hypofrontality in attention deficit hyperactivity disorder during higher-order motor control: a study with functional MRI. Am J Psychiatry. 1999;156(6):891-896.

9. Zang YF, Jin Z, Weng XC, et al. Functional MRI in attentiondeficit hyperactivity disorder: evidence for hypofrontality. Brain Dev. 2005;27(8):544-550.

10. Hart H, Radua J, Nakao T, Mataix-Cols D, Rubia K. Meta-analysis of functional magnetic resonance imaging studies of inhibition and attention in attention-deficit/hyperactivity disorder: exploring taskspecific, stimulant medication, and age effects. JAMA Psychiatry. 2013;70(2):185-198.

11. Denckla MB. Revised neurological examination for subtle signs (1985). Psychopharmacol Bull. 1985;21(4):773-800.

12. Conners CK. Parent Symptom Questionnaire. Psychopharm Bull. 1985;21(4):816-822.

13. Palct I, Ptacek R, Koudelova J. Hyperkineticka Porucha a Poruchy Chovani [Hyperkinetic Disease and Behavioral Disorders]. Prague, Czechoslovakia: Grada Publishing; 2007. Czech.
14. Arnsten AF. Toward a new understanding of attention-deficit hyperactivity disorder pathophysiology: an important role for prefrontal cortex dysfunction. CNS Drugs. 2009;23 Suppl 1:33-41.

15. Shaw P, Rabin C. New insights into attention-deficit/hyperactivity disorder using structural neuroimaging. Curr Psychiatry Rep. 2009;11(5):393-398.

16. Makris N, Biederman J, Monuteaux MC, Seidman LJ. Towards conceptualizing a neural systems-based anatomy of attention-deficit/ hyperactivity disorder. Dev Neurosci. 2009;31(1-2):36-49.

17. Baillieux H, De Smet HJ, Paquier PF, De Deyn PP, Mariën P. Cerebellar neurocognition: insights into the bottom of the brain. Clin Neurol Neurosurg. 2008;110(8):763-773.

18. Konczak J, Schoch B, Dimitrova A, Gizewski E, Timmann D. Functional recovery of children and adolescents after cerebellar tumour resection. Brain. 2005;128(Pt 6):1428-1441.

19. Tersteeg MC, Marple-Horvat DE, Loram ID. Cautious gait in relation to knowledge and vision of height: is altered visual information the dominant influence? J Neurophysiol. 2012;107(10):2686-2691.

20. Carpenter MG, Frank JS, Silcher CP. Surface height effects on postural control: a hypothesis for a stiffness strategy for stance. J Vestib Res. 1999;9(4):277-286.

21. Carpenter MG, Frank JS, Silcher CP, Peysar GW. The influence of postural threat on the control of upright stance. Exp Brain Res. 2001;138(2):210-218.

22. Sibley KM, Carpenter MG, Perry JC, Frank JS. Effects of postural anxiety on the soleus H-reflex. Hum Mov Sci. 2007;26(1):103-112.

23. Gatev P, Thomas S, Lou JS, Lim M, Hallett M. Effects of diminished and conflicting sensory information on balance in patients with cerebellar deficits. Mov Disord. 1996;11(6):654-664.
Neuropsychiatric Disease and Treatment

\section{Publish your work in this journal}

Neuropsychiatric Disease and Treatment is an international, peerreviewed journal of clinical therapeutics and pharmacology focusing on concise rapid reporting of clinical or pre-clinical studies on a range of neuropsychiatric and neurological disorders. This journal is indexed on PubMed Central, the 'PsycINFO' database and CAS.

\section{Dovepress}

The manuscript management system is completely online and includes a very quick and fair peer-review system, which is all easy to use. Visit http://www.dovepress.com/testimonials.php to read real quotes from published authors. 